\title{
Pharmacokinetics and pharmacodynamics of low-dose methotrexate in the treatment of psoriasis
}

\author{
Jaroslav Chládek,' Jiøí Grim,' Jiøina Martínková,' Marie Šimková, ' Jaroslava Vanièková, ${ }^{2}$ \\ Vira Koudelková ${ }^{2}$ \& Marie Noièková \\ ${ }^{1}$ Department of Pharmacology, Faculty of Medicine Charles University, Hradec Králové and ${ }^{2}$ Department of Dermatology, University Hospital, \\ Hradec Králové, Czech Republic
}

\begin{abstract}
Aims The aim of this 13 week, randomized, parallel-group study was to evaluate the relationship between the pharmacokinetics (PK) and pharmacodynamics (PD) of low-dose intermittent oral methotrexate (LDMTX) in patients with psoriasis.

Methods Twenty-four psoriatic patients (15 male and 9 female, aged $31-73$ years) were given weekly doses of MTX doses of either $7.5 \mathrm{mg}$ or $15 \mathrm{mg}$ with each dose divided into three aliquots given at $12 \mathrm{~h}$ intervals. The pharmacokinetics of MTX were evaluated at weeks 1 and 13. Skin impairment was assessed using the PASIscoring system (The Psoriasis Area and Severity Index) at baseline and at weeks 5, 9 and 13 of therapy. Haematological and biochemistry tests were also performed at these times.

Results The comparison of the areas under the plasma concentration-time curve $\left(\right.$ AUC $\left._{\mathrm{MTX}}\right)$ after the first and third weekly doses showed that the extent of MTX accumulation in plasma was only about $12 \%$. Two-way ANOVA (factors: subject and the week of therapy) on the log-transformed $\mathrm{AUC}_{\mathrm{MTX}}$ showed no effect of the week of therapy $(P>0.8)$. Moreover, the intraindividual variability in the $\mathrm{AUC}_{\mathrm{MTX}}$ was at least 4 -fold less than the interindividual variability $(F$-test; $P<0.01)$. The steady-state total plasma clearance of MTX ranged from 5.0 to $18.21 \mathrm{~h}^{-1}$ and was proportional to the renal clearance $\left(r^{2}=0.45, P<0.001\right)$ which accounted for $65 \pm 20 \%$ of the former. The renal clearance of 7-OHMTX was approximately $4-8 \%$ of that of the parent compound. PK/PD analysis revealed a highly significant inverse relationship between PASI (expressed as a percent of the initial value) and a steady-state $A_{U C} C_{M T X}$ $\left(r_{\mathrm{s}}=-0.65, P<0.001\right)$. Seventeen subjects ( 8 from the $7.5 \mathrm{mg}$ group and 9 from the $15 \mathrm{mg}$ group MTX, $P=0.67$ ) achieved a greater than $50 \%$ decrease in the initial PASI score and were classified as responders. Thirteen of 14 subjects with $\operatorname{AUC}(24,36 \mathrm{~h}) \geq 700 \mathrm{nmol}^{-1} \mathrm{~h}$ responded to pharmacotherapy. Conversely, only 4 out of 10 subjects with $\mathrm{AUC}(24,36 \mathrm{~h})<700 \mathrm{nmol}^{-1} \mathrm{~h}$ were responders $(P<0.01$, Fisher's exact test).
\end{abstract}

Conclusions A strong correlation was observed between the pharmacokinetics (AUC ${ }_{\mathrm{MTX}}$ at the steady state) and antipsoriatic effect (PASI-score) of LDMTX. The considerable interindividual variability and low intraindividual variability in MTX pharmacokinetics support a role for therapeutic monitoring and dose individualization at the start of pharmacotherapy. The results of this study suggest that a steady state $\mathrm{AUC}_{\mathrm{MTX}}$ values of $700 \mathrm{nmol} 1^{-1} \mathrm{~h}$ and higher are associated with a significantly better success rate of antipsoriatic therapy than lower values.

Keywords: AUC, methotrexate, PASI score, psoriasis

Correspondence: Jaroslav Chládek, MD, Department of Pharmacology, Faculty of Medicine Charles University, Hradec Králové, Šimkova 870, Czech Republic. Tel.: 00420495816283; E-mail: grimj@|fhk.cuni.cz

Received 15 August 2001, accepted 28 April 2002.

\section{Introduction}

Low-dose methotrexate (LDMTX) is an established and effective immunosuppressive and anti-inflammatory therapy for generalized and palmoplantar psoriasis resistant to 
tar, retinoids, psoralens and UVA-light. The drug is also effective in the treatment of other autoimmune diseases, such as rheumatoid arthritis, sarcoidosis or Crohn's disease [1-3]. The most important problems with LDMTX therapy are first to induce remission of disease or at least to decrease its symptoms to an acceptable level, second to attain the lowest maintenance dose, and third to maintain remission over a long period without undue toxicity. LDMTX is commonly administered orally, intramuscularly or subcutaneously. However, the most convenient regimen in adults is to start therapy with intermittent oral administration of 5-10 $\mathrm{mg}$ once a week. If, after 6-8 weeks, the response is not adequate and no adverse effects are present, the weekly dose can be gradually increased to $25 \mathrm{mg}$. Higher dosages should be employed cautiously due to a reduced bioavailability and an increased risk of toxicity [4, 5]. To lessen the acute adverse effects of MTX like nausea, gastrointestinal symptoms and headache, a triple dose regimen is used, in which the weekly dose is divided into three aliquots given at $12 \mathrm{~h}$ intervals [6,7].

LDMTX therapy is associated with large interindividual variability in its antipsoriatic effect, which can be mainly attributed to marked differences in pharmacokinetics between patients $[2,3,7,8]$.

In a previous small study $(n=10)$, we observed a significant and strong correlation between the area under the plasma MTX concentration-time curve (AUC $\mathrm{ATX}_{\mathrm{MT}}$ ) and its skin-clearing effect (PASI-score) after 3 months of intermittent oral dosing with $15 \mathrm{mg}$ once a week [8]. The primary goal of the present study was first to confirm whether a similar relationship exists if the same weekly dose is administered using the triple dose regimen. Second, we aimed to establish a target value of

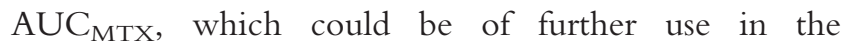
individualization of dosing. Finally, we have investigated the pharmacokinetics of MTX and 7-hydroxymethotrexate (7-OHMTX) in psoriatic patients given the divided dose schedule.

\section{Methods}

The study was performed between March 1999 and October 2000 in the Department of Dermatology, University Hospital, Hradec Králové, and the Department of Pharmacology, Faculty of Medicine, Charles University, Hradec Králové, the Czech Republic. The study protocol was approved by the Regional Ethics Committee. Twenty-four psoriatic patients who failed to respond to previous conventional therapy with tar, retinoids, psoralens and phototherapy were recruited. Prior to inclusion in the study all patients gave their informed consent. Exclusion criteria consisted of clinically relevant abnormalities according to known hepatotoxicity and myelotoxicity [6]. Each patient had a normal full blood cell count, normal liver function tests (including the activities of transaminases, alkaline phosphatase and $\gamma$-glutamyltranspeptidase) and creatinine clearance $\left(\mathrm{CL}_{\mathrm{CR}}\right)$. Ultrasonographic examination of the liver was also performed before the study.

\section{Study protocol}

The patients were enrolled in a 13 week prospective parallel-group study, and were randomly assigned to two groups each of which was given either $7.5 \mathrm{mg}$ or $15 \mathrm{mg}$ MTX a week. The weekly dose was divided into three aliquots of either $2.5 \mathrm{mg}(5.5 \mu \mathrm{mol})$ or $5 \mathrm{mg}$ (11 $\mu \mathrm{mol})$ given at $12 \mathrm{~h}$ intervals. During weeks 1 and 13, drugs were given in the Department of Dermatology. At all other times patients took their MTX therapy at home. For physical and laboratory evaluation, each patient was admitted to the hospital 1 day before the MTX administration for a 3 day stay. Patients refrained from alcohol for at least $24 \mathrm{~h}$ before the study. Xanthine beverages and milk were avoided $12 \mathrm{~h}$ before each drug administration and during the study days. Concomitant pharmacotherapy in some patients included antihypertensive drugs $(\beta$-adrenoceptor blockers, thiazide diuretics), statins, oral hypoglycaemic agents (sulphonylurea derivatives) and antiasthmatics ( $\beta_{2}$-sympathomimetics). None of these drugs has been reported to change the pharmacokinetics of LDMTX. Participants fasted overnight but were allowed to drink water without any restriction. A bolus oral dose of MTX (Methotrexate Lachema, Brno, the Czech Republic) was administered in the morning (at $07.00 \mathrm{~h}$ ) $0.5 \mathrm{~h}$ after a light standardized breakfast. No food was allowed until $4 \mathrm{~h}$ after the drug administration. The next doses of MTX were given at $19.00 \mathrm{~h}$ and at $07.00 \mathrm{~h}$ the following day.

The pharmacokinetics of MTX were investigated after doses no. 1, 2 and 3 (at week 1) and 37, 38 and 39 (at week 13). Venous blood samples were drawn into heparinized tubes at $0 \mathrm{~h}, 1 \mathrm{~h}, 2 \mathrm{~h}, 4 \mathrm{~h}, 8 \mathrm{~h}$ and $12 \mathrm{~h}$ after the first and third doses of MTX (both given at $07.00 \mathrm{~h}$ ) and at $2 \mathrm{~h}$ after the second dose (administered at $19.00 \mathrm{~h}$ ). All plasma samples were centrifuged $\left(10 \mathrm{~min}, 1500 \mathrm{~g}, 4^{\circ} \mathrm{C}\right.$ ) within $1 \mathrm{~h}$ after sampling and stored at $-20^{\circ} \mathrm{C}$ until analysis (no longer than 3 months later). Patients were asked to empty their bladder before MTX administration. Urine was collected for $12 \mathrm{~h}$ after each of the three doses. During each collection, the urine container was kept in a refrigerator at $4^{\circ} \mathrm{C}$. After the end of each collection interval, the urine was gently mixed, the weight was recorded and aliquots of urine were stored at $-20^{\circ} \mathrm{C}$ until analysis. 
The grade of skin impairment of all subjects was evaluated by the same specialist in dermatology at baseline (week 1) and at 4 week intervals (weeks 5, 9 and 13 of pharmacotherapy) according to the PASIscoring system (The Psoriasis Activity and Severity Index; [9]. The score gives a measure of the clinical degree of psoriasis (0-72). PASI assessments were performed blind with respect to the pharmacokinetic analyses. The safety of therapy was evaluated using haematological data (total erythrocyte, leucocyte and platelet counts) and biochemistry (bilirubin, transaminases, $\gamma$-glutamyltranspeptidase, creatinine, urea, haemoglobin, albumin, CRP).

\section{Assay methods}

MTX and its 7-hydroxy metabolite (7-OHMTX) were determined by h.p.l.c. using fluorometric detection after postcolumn derivatization by u.v. light [10]. 7-OHMTX (99\% pure by h.p.l.c.) was synthesized using rabbit liver aldehyde oxidase [11]. Plasma samples were deproteinized with a mixture of $0.8 \mathrm{M}$ trichloroacetic acid, dissolved in $40 \%$ acetic acid. After centrifugation $(2500 \mathrm{~g}, 10 \mathrm{~min})$, 20-50 $\mu$ l aliquots of the supernatant were injected into the h.p.l.c. column. The recovery of both compounds was approximately 90\%. MTX and 7-OHMTX were isolated from urine a solid-phase extraction procedure [12]. The linear range of detector response in plasma and urine

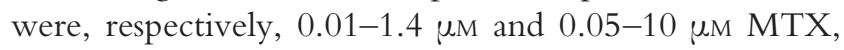
and $0.005-0.80 \mu \mathrm{M}$ and $0.01-2.0 \mu \mathrm{M}$ 7-OHMTX. Based on the analysis of MTX and 7-OHMTX calibration standards, the interday coefficients of variation were less than $9 \%$ in plasma and less than $10 \%$ in urine. In plasma, the coefficients of variation for interday precision for low $(0.020 \mu \mathrm{M})$ and high $(0.400 \mu \mathrm{M})$ quality control samples were, respectively, $7.1 \%$ and $5.8 \%$ (MTX) and $9.3 \%$ and $6.7 \%$ (7-OHMTX). In urine, the coefficients of variation for interday precision for low $(0.100 \mu \mathrm{M})$ and high $(1.50 \mu \mathrm{M})$ quality control samples were, respectively, $8.1 \%$ and $4.9 \%$ (MTX) and 8.5\% and 6.2\% (7-OHMTX). In the course of the study, the analytical laboratory was a member of the United Kingdom National External Quality Assessment Scheme for methotrexate in serum. Two samples with MTX concentration less than $1 \mu \mathrm{mol} 1^{-1}$ were analysed and reported to the scheme. Their spiked values were $0.25 \mu \mathrm{mol} 1^{-1}$ and $0.59 \mu \mathrm{mol} 1^{-1}$ and the corresponding assayed values were $0.22 \mu \mathrm{mol}^{-1}$ and $0.58 \mu \mathrm{mol} 1^{-1}$. The results of a formal stability study have shown that both MTX and 7-OHMTX are stable under the sampling and storage conditions used in this study.

The protein binding of MTX in plasma was determined by ultrafiltration at $37^{\circ} \mathrm{C}$ (Ultrafree-MS filters, Millipore, Milford, MA).

\section{Pharmacokinetic analysis}

Pharmacokinetic parameters of MTX and 7-OHMTX were estimated by use of standard noncompartmental methods. Maximum concentration in plasma $\left(C_{\max }\right)$ and time to reach maximum concentration $\left(t_{\max }\right)$ were determined directly from the observed data. AUC $\mathrm{ATX}_{\mathrm{MTX}}$ over the dosing interval (12 h) was calculated by the linear trapezoidal method. Apparent total clearance $(\mathrm{CL} / \mathrm{F})$ of MTX at steady state was obtained by dividing the dose with the $\operatorname{AUC}(24,36 \mathrm{~h})$. The renal clearances $\left(\mathrm{CL}_{\mathrm{R}}\right)$ of MTX and 7-OHMTX were calculated as the amount excreted in urine over $12 \mathrm{~h}$ divided by the corresponding $\mathrm{AUC}(24,36 \mathrm{~h}) . \mathrm{CL}_{\mathrm{CR}}$ was calculated as the product of the urine concentration of creatinine and the urine flow rate (over $12 \mathrm{~h}$ ) divided by the creatinine concentration in plasma obtained at $8 \mathrm{~h}$ after MTX administration.

\section{Statistical analysis}

Student's t-test or Mann-Whitney U-test was used for intergroup comparisons of subject characteristics. Fisher's exact test was used to compare the proportions of sexes and of responders and nonresponders with pharmacotherapy between the groups. The within-subject and between-subject variability in pharmacokinetic parameters after the first $\left(\mathrm{AUC}(0,12 \mathrm{~h}), C_{\max }^{1}\right)$, and third (AUC(24,36 h), $\left.C_{\max }^{3}\right)$ weekly MTX doses, were compared using a two-way analysis of variance (ANOVA, factors: subject and week of the study). ANOVA was performed on dose-normalized pharmacokinetic variables, which were log-transformed before analysis. A repeated measures ANOVA was performed to compare the dosenormalized plasma concentrations at $12 \mathrm{~h}, 24 \mathrm{~h}$ and $36 \mathrm{~h}$, i.e. at the end of dosing interval $\left(C_{\min }\right)$, after the three weekly doses in the weeks 1 and 13 of the study. Simple linear regression or Spearman's rank correlation was performed in order to examine the relationship between the variables under study. All calculations were carried out by the Statistica for Windows software (Statsoft, Inc., Tulsa, USA).

\section{Results}

Demographic data are shown in Table 1. The mean (s.d.) MTX concentration-time profiles in plasma obtained at study weeks 1 and 13 are shown in Figure 1. Substantial variability was observed in plasma MTX concentrations and in the corresponding pharmacokinetic variables (Table 2). The dose-normalized areas under the plasma concentration-time curve and maximum concentrations observed after the first $\left(\operatorname{AUC}(0,12 \mathrm{~h}), C_{\max }^{1}\right)$ and third 
weekly doses (AUC(24,36 h), $C_{\text {max }}^{3}$ ) varied 3.3-4.8-fold between subjects. The comparison of the AUC after the first and third weekly doses showed that the extent of MTX accumulation in plasma was low. The median

Table 1 Demographic characteristics of the patients and outcome of therapy.

\begin{tabular}{|c|c|c|c|}
\hline \multirow[b]{2}{*}{ Characteristic } & \multicolumn{2}{|c|}{ Methotrexate } & \multirow[b]{2}{*}{$\mathrm{P}$} \\
\hline & $7.5 \mathrm{mg} \mathrm{week^{-1 }}$ & $15 \mathrm{mg}^{\text {week }^{-1}}$ & \\
\hline Age (years) & $49.9 \pm 11.6$ & $56.3 \pm 12.3$ & $0.20^{\mathrm{a}}$ \\
\hline Sex M/F & $5 / 7$ & $10 / 2$ & $0.04^{\mathrm{b}}$ \\
\hline Weight $(\mathrm{kg})$ & $80.8 \pm 16.9$ & $97.1 \pm 22.3$ & $0.05^{\mathrm{a}}$ \\
\hline BSA $\left(m^{2}\right)$ & $1.9 \pm 0.2$ & $2.2 \pm 0.2$ & $0.02^{\mathrm{a}}$ \\
\hline $\mathrm{CL}_{\mathrm{CR}}\left(1 \mathrm{~h}^{-1}\right)$ & $6.3 \pm 2.1$ & $7.4 \pm 2.5$ & $0.23^{\mathrm{a}}$ \\
\hline Baseline PASI & $44.8 \pm 26.2$ & $38.6 \pm 25.4$ & $0.23^{\mathrm{c}}$ \\
\hline Final PASI (\%) & $29.9 \pm 16.6$ & $28.0 \pm 31.4$ & $0.13^{\mathrm{c}}$ \\
\hline Responders (\%) & 66.7 & 75.0 & $0.65^{\mathrm{a}}$ \\
\hline
\end{tabular}

${ }^{\mathrm{a}}$ Student's $t$-test; ${ }^{\mathrm{b}}$ Fisher's test; ${ }^{\mathrm{c}}$ Mann-Whitney test.
(25\% quartile, $75 \%$ quartile) accumulation ratios of the areas $\mathrm{AUC}(24,36 \mathrm{~h})$ to $\mathrm{AUC}(0,12 \mathrm{~h})$ were 1.11 (1.05, $1.21)$ and $1.13(1.03,1.25)$ at the weeks 1 and 13 , respectively. Similarly, the accumulation ratios of the $C_{\max }$ values $C_{\max }^{3}$ to $C_{\max }^{1}$ were $1.10(0.97,1.20)$ and 1.05 $(0.97,1.24)$ at the weeks 1 and 13 , respectively (Table 2$)$.

To compare the within-subject and between-subject variability, a two-way ANOVA (factors: subject and week of the study) was performed on dose-normalized pharmacokinetic variables $\left(\operatorname{AUC}(0,12 \mathrm{~h}), C_{\max }^{1}, \operatorname{AUC}(24,36 \mathrm{~h})\right.$, $\left.C_{\max }^{3}\right)$, which were log-transformed before analysis. The ANOVA results for all these variables showed no effect of the week of the study (F-test, $P>0.8$ ). Moreover, withinsubject variability of these variables was at least 4-fold less than between-subject variability $(F$-test, $P<0.001)$. This indicates that the pharmacokinetic variables observed at week 1 are representative of the entire study period and can be used in the correlation analysis as possible predictors of the skin-clearing effect of the drug.

Table 2 Median (25\% quartile-75\% quartile) pharmacokinetic parameters after low-dose oral methotrexate in psoriatic patients. The weekly dose was divided into three aliquots of either $2.5 \mathrm{mg}(5.5 \mu \mathrm{mol})$ or $5 \mathrm{mg}(11 \mu \mathrm{mol})$ given at $12 \mathrm{~h}$ intervals. Samples were taken after the first and third doses at weeks 1 and 13 .

\begin{tabular}{|c|c|c|c|c|}
\hline \multirow[b]{2}{*}{ Dose } & \multicolumn{2}{|c|}{ Week 1} & \multicolumn{2}{|c|}{ Week 13} \\
\hline & $2.5 \mathrm{mg}$ & $5 \mathrm{mg}$ & $2.5 \mathrm{mg}$ & $5 \mathrm{mg}$ \\
\hline $\operatorname{AUC}(0,12 \mathrm{~h})\left(\mathrm{nmol} \mathrm{l} \mathrm{l}^{-1} \mathrm{~h}\right)$ & $571(433-793)$ & $892(693-992)$ & $522(462-750)$ & $724(665-952)$ \\
\hline$C_{\max }^{1}\left(\mathrm{nmol}^{-1}\right)$ & $106(84-133)$ & $172(148-200)$ & $105(89-131)$ & $150(118-200)$ \\
\hline$t_{\max }^{1}(\mathrm{~h})$ & $2(1-2)$ & $1(1-2)$ & $2(1-2)$ & $2(1-2)$ \\
\hline $\operatorname{AUC}(24,36 \mathrm{~h})\left(\mathrm{nmol} \mathrm{l}{ }^{-1} \mathrm{~h}\right)$ & $600(499-837)$ & $1037(859-1137)$ & $611(488-743)$ & $930(770-1132)$ \\
\hline$C_{\max }^{3}\left(\mathrm{nmol} \mathrm{1} 1^{-1}\right)$ & $117(94-137)$ & $172(161-215)$ & $95(88-152)$ & $157(142-200)$ \\
\hline$t_{\max }^{3}(\mathrm{~h})$ & $2(1-2)$ & $2(1-2)$ & $1(1-2)$ & $2(1-2)$ \\
\hline
\end{tabular}
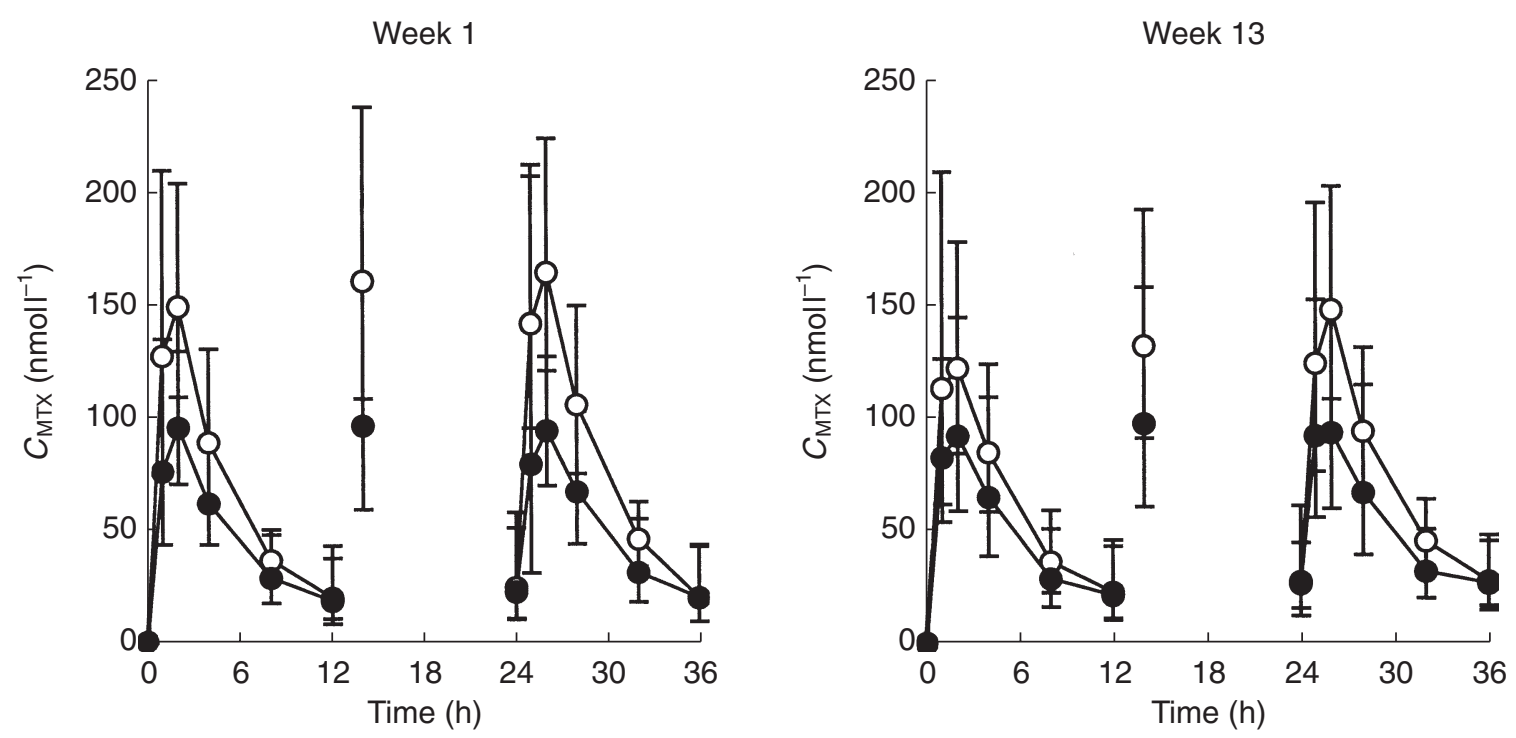

Figure 1 Geometric mean (exponent [mean \pm s.d., ln-data]) plasma methotrexate concentration-time data after three oral doses of either $2.5 \mathrm{mg}(5.5 \mu \mathrm{mol})(\mathbf{O})$ or $5 \mathrm{mg}(11 \mu \mathrm{mol})(\bigcirc)$ at $12 \mathrm{~h}$ intervals. Weeks 1 and 13 refer to the 1 st and 13 th weeks of intermittent dosing. 
The effect of time on the dose-normalized $C_{\min }$ was significant $(F$-test, $P<0.01) . C_{\min }$ after the second and third weekly doses differed from that after the first dose (Tukey HSD test, $P<0.05$ ), but did not differ between each other $(P>0.3)$. These results suggest that a steady state of MTX plasma concentrations may be reached after the third weekly dose (Figure 1).

The mean (s.d.) 7-OH MTX concentration-time profiles in plasma obtained at weeks 1 and 13 are shown in Figure 2. The corresponding pharmacokinetic variables are summarized in Table 3. The median (25\% quartile, $75 \%$ quartile) accumulation ratios of the areas $\mathrm{AUC}(24,36 \mathrm{~h})$ to $\mathrm{AUC}(0,12 \mathrm{~h})$ were $2.7(2.4,3.1)$ and $2.3(2.1,2.9)$ at weeks 1 and 13 , respectively. The accumulation ratios of the $C_{\max }$ values $C_{\max }^{3}$ to $C_{\max }^{1}$ were $2.3(2.1,2.5)$ and $2.1(1.9,2.2)$ at the weeks 1 and 13 , respectively.

The protein binding of MTX was concentration independent as assessed from 96 samples containing drug over a concentration range of $0.014-0.24 \mu \mathrm{mol} 1^{-1}$. The mean (s.d.) bound fraction of MTX was $0.53 \pm 0.06$ at week 1 , and $0.52 \pm 0.07$ at week 13 . The metabolite concentrations in plasma ultrafiltrates were too low to be accurately determined indicating greater than $90 \%$ binding.

Urinary excretion data for MTX and 7-OHMTX are shown in Table 4. Within $12 \mathrm{~h}$ after the first drug administration, the median (25\% quartile-75\% quartile) urinary excretion of MTX was 66.9\% (65.0\%, 75.8\%) of the dose in the group receiving the divided dose $2.5 \mathrm{mg}$ and $64.3 \%(55.6 \%, 69.7 \%)$ in the group receiving the $5 \mathrm{mg}$ group divided dose (Table 4). The oral clearance of MTX and renal clearances of MTX and 7-OHMTX at steady state are listed in the Table 5. At week 1, the steady-state oral clearance of MTX ranged between 5.0 and 18.2 and was proportional to its $\mathrm{CL}_{\mathrm{R}} \quad\left(r^{2}=0.45, \quad P<0.001\right)$. $\mathrm{CL}_{\mathrm{R}}$ accounted for $69 \pm 14 \%$ of the oral clearance in the group receiving

Week 1

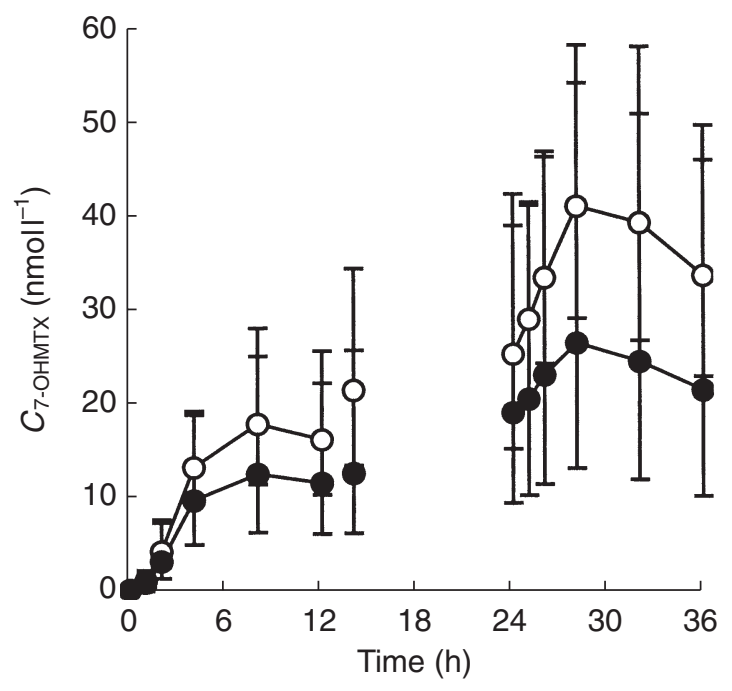

Week 13

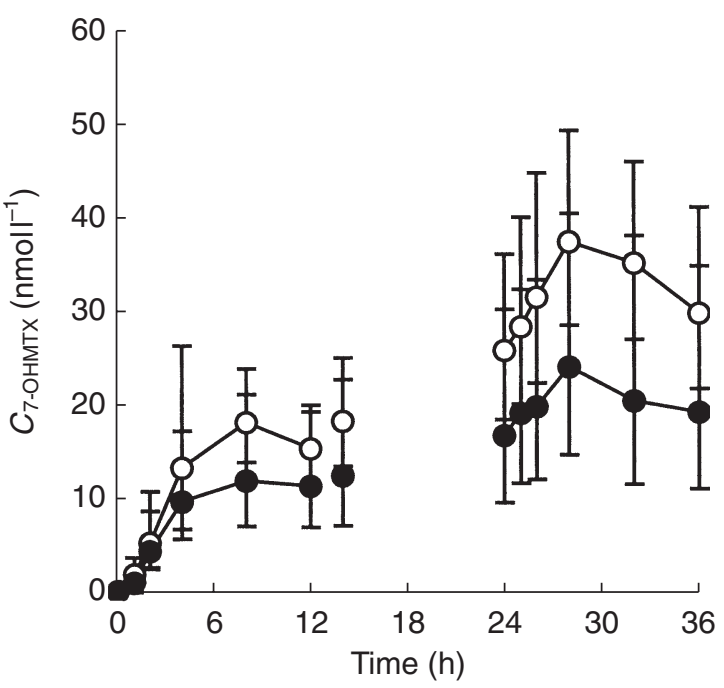

Figure 2 Geometric mean (exponent [mean \pm s.d., ln-data]) plasma 7-hydroxymethotrexate concentration-time data after three oral doses of either $2.5 \mathrm{mg}(5.5 \mu \mathrm{mol})(\mathbf{O})$ or $5 \mathrm{mg}(11 \mu \mathrm{mol})(\bigcirc)$ methotrexate at $12 \mathrm{~h}$ intervals. Weeks 1 and 13 refer to the $1 \mathrm{st}$ and 13 th weeks of intermittent dosing.

Table 3 Median (25\% quartile-75\% quartile) pharmacokinetic parameters of 7-hydroxymethotrexate in psoriatic patients on low-dose oral methotrexate. The weekly dose was divided into three aliquots of either $2.5 \mathrm{mg}(5.5 \mu \mathrm{mol})$ or $5 \mathrm{mg}(11 \mu \mathrm{mol})$ given at $12 \mathrm{~h}$ intervals. Samples were taken after the first and third doses at weeks 1 and 13 .

\begin{tabular}{|c|c|c|c|c|}
\hline \multirow[b]{2}{*}{ Dose } & \multicolumn{2}{|c|}{ Week 1} & \multicolumn{2}{|c|}{ Week 13} \\
\hline & $2.5 \mathrm{mg}$ & $5 m g$ & $2.5 \mathrm{mg}$ & $5 m g$ \\
\hline $\operatorname{AUC}(0,12 \mathrm{~h})\left(\mathrm{nmol} \mathrm{l}^{-1} \mathrm{~h}\right)$ & $113(76-127)$ & $140(114-198)$ & $86(72-152)$ & $154(147-239)$ \\
\hline$C_{\max }^{1}\left(\operatorname{nmol~}^{-1}\right)$ & $14.0(10.4-14.7)$ & $16.3(13.8-25.2)$ & $10.5(6.6-13.6)$ & $20.3(15.3-27.3)$ \\
\hline$t_{\max }^{1}(\mathrm{~h})$ & $8(8-8)$ & $8(8-8)$ & $8(8-12)$ & $8(8-8)$ \\
\hline $\operatorname{AUC}(24,36 \mathrm{~h})\left(\mathrm{nmol} \mathrm{l}^{-1} \mathrm{~h}\right)$ & $305(176-334)$ & $430(358-563)$ & $196(148-304)$ & $404(352-639)$ \\
\hline$C_{\max }^{3}\left(\operatorname{nmol~1~}^{-1}\right)$ & $29.5(19.2-31.7)$ & $39.4(35.1-55.0)$ & $19.9(16.0-28.4)$ & $36.2(30.6-55.0)$ \\
\hline$t_{\max }^{3}(\mathrm{~h})$ & $4(4-8)$ & $4(4-8)$ & $4(4-5)$ & $4(4-4)$ \\
\hline
\end{tabular}


Table 4 Median (25\% quartile-75\% quartile) of urinary excretion (UE, $\mu$ mol) and 36 h urinary recovery (UR, \% of the dose) of methotrexate (MTX) and 7-hydroxymethotrexate (7-OHMTX) in psoriatic patients on low-dose oral MTX. The weekly dose was divided into three aliquots of either $2.5 \mathrm{mg}(5.5 \mu \mathrm{mol})$ or $5 \mathrm{mg}(11 \mu \mathrm{mol})$ given at $12 \mathrm{~h}$ intervals. Urine collection was performed over $12 \mathrm{~h}$ following each of the three doses at weeks 1 and 13 .

\begin{tabular}{|c|c|c|c|c|}
\hline \multirow[b]{2}{*}{ Dose } & \multicolumn{2}{|c|}{ Week 1} & \multicolumn{2}{|c|}{ Week 13} \\
\hline & $2.5 \mathrm{mg}$ & $5 m g$ & $2.5 \mathrm{mg}$ & $5 \mathrm{mg}$ \\
\hline $\mathrm{UE}(0,12 \mathrm{~h}) \operatorname{MTX}(\mu \mathrm{mol})$ & $3.7(3.6-4.2)$ & $7.4(7.2-8.3)$ & $3.4(2.9-4.7)$ & $8.0(5.6-8.8)$ \\
\hline $\mathrm{UE}(12,24 \mathrm{~h})$ & $3.1(2.6-3.9)$ & $7.0(6.1-7.4)$ & $3.2(2.1-3.7)$ & $6.7(5.3-8.0)$ \\
\hline $\mathrm{UE}(24,36 \mathrm{~h})$ & $4.1(3.2-5.2)$ & $7.2(6.2-8.8)$ & $4.3(3.8-5.3)$ & $8.7(7.5-10.5)$ \\
\hline $\mathrm{UE}(0,12 \mathrm{~h})$ 7-OHMTX ( $\mu \mathrm{mol})$ & $0.06(0.04-0.08)$ & $0.10(0.9-0.17)$ & $0.08(0.06-0.12)$ & $0.12(0.08-0.18)$ \\
\hline $\mathrm{UE}(12,24 \mathrm{~h})$ & $0.08(0.05-0.12)$ & $0.18(0.10-0.24)$ & $0.08(0.07-0.17)$ & $0.19(0.11-0.30)$ \\
\hline $\mathrm{UE}(24,36 \mathrm{~h})$ & $0.20(0.13-0.26)$ & $0.39(0.26-0.52)$ & $0.19(0.17-0.20)$ & $0.26(0.15-0.33)$ \\
\hline $\mathrm{UR}(0,36$ h) MTX (\%) & $69.3(60.1-76.7)$ & $63.2(59.1-73.6)$ & $58.0(45.6-76.7)$ & $73.2(61.3-84.2)$ \\
\hline UR $(0,36$ h) 7-OH MTX (\%) & $2.4(1.4-2.8)$ & $2.2(0.9-2.5)$ & $2.6(1.8-3.1)$ & $1.7(1.2-2.0)$ \\
\hline
\end{tabular}

Table 5 Median (25\% quartile-75\% quartile) of $(\mathrm{CL} / \mathrm{F})$ and renal $\left(\mathrm{CL}_{\mathrm{R}}\right)$ clearances of methotrexate (MTX) and renal clearance of 7-hydroxymethotrexate (7-OHMTX) in psoriatic patients following oral administration of $2.5 \mathrm{mg}(5.5 \mu \mathrm{mol})$ and $5 \mathrm{mg}(11 \mu \mathrm{mol}) \mathrm{methotrexate}$. The drug was administered once a week with the weekly dose divided into three aliquots given at $12 \mathrm{~h}$ intervals. Clearances were estimated after the third doses administered at weeks 1 and 13 .

\begin{tabular}{|c|c|c|c|c|}
\hline \multirow[b]{2}{*}{ Dose } & \multicolumn{2}{|c|}{ Week 1} & \multicolumn{2}{|c|}{ Week 13} \\
\hline & $2.5 \mathrm{mg}$ & $5 m g$ & $2.5 \mathrm{mg}$ & $5 m g$ \\
\hline $\mathrm{CL} / F\left(1 \mathrm{~h}^{-1}\right) \mathrm{MTX}$ & $9.2(6.6-11.3)$ & $10.6(9.7-12.8)$ & $10.5(7.7-11.2)$ & $11.9(9.2-14.7)$ \\
\hline $\mathrm{CL}_{\mathrm{R}}\left(1 \mathrm{~h}^{-1}\right) \mathrm{MTX}$ & $7.1(4.6-9.3)$ & $8.8(6.5-10.0)$ & $6.6(5.7-6.9)$ & $8.8(7.6-10.0)$ \\
\hline $\mathrm{CL}_{\mathrm{R}}\left(\mathrm{l} \mathrm{h}^{-1}\right) 7-\mathrm{OH} \mathrm{MTX}$ & $0.78(0.57-1.10)$ & $0.64(0.50-0.86)$ & $0.80(0.66-0.90)$ & $0.71(0.54-1.05)$ \\
\hline
\end{tabular}

the divided dose $2.5 \mathrm{mg}$ and for $59 \pm 20 \%$ in those receiving the $5 \mathrm{mg}$ divided dose. At week 13, similar relationships between the two clearances were found. There was a significant correlation $\left(r^{2}=0.49\right.$, $P<0.0001)$ between $\mathrm{CL}_{\mathrm{R}}$ and $\mathrm{CL}_{\mathrm{CR}}$. The renal clearance of 7-OHMTX was 4-8\% of that of the parent compound (Table 5).

At week 13, considerable intersubject variability in the skin clearing effect of LDMTX therapy was evident (Figure 3). There was a highly significant inverse relationship between PASI (in percent of the initial value) and AUC $(24,36 \mathrm{~h})\left(r_{\mathrm{s}}=-0.65, P<0.001\right.$; Figure 4). Seventeen subjects ( 8 from the group receiving $2.5 \mathrm{mg}$ and 9 from the group receiving $5 \mathrm{mg}, P=0.67$, Fisher's exact test) achieved a greater than $50 \%$ decrease in the initial PASI-score and were classified as responders. Based on MTX pharmacokinetics at week 1, the entire study group was separated arbitrarily into two groups, one group with an $\operatorname{AUC}(24,36 \mathrm{~h}) \geq 700 \mathrm{nmol} 1^{-1} \mathrm{~h}$ and the other with an $\operatorname{AUC}(24,36 \mathrm{~h})<700 \mathrm{nmol} 1^{-1} \mathrm{~h}$. Thirteen of the 14 subjects with an $\operatorname{AUC}(24,36 \mathrm{~h}) \geq 700 \mathrm{nmol}^{-1} \mathrm{~h}$ responded to pharmacotherapy. Conversely, only 4 out of 10 subjects with an $\operatorname{AUC}(24,36 \mathrm{~h})<700 \mathrm{nmol}^{-1} \mathrm{~h}$ were responders. The difference in proportions of responders between the two groups was highly significant $(P<0.01$, Fisher's exact test $)$.

The medication was well tolerated and safe. In the course of the study, only one patient from the group receiving $11 \mu \mathrm{mol}$ complained of a headache. Transient hepatotoxicity occurred in two patients in the group receiving $5.5 \mu \mathrm{mol}$ and in three patients in the group receiving $11 \mu \mathrm{mol}$ soon after the start of LDMTX therapy. However, the activities of aminotransferases (ALT and AST) were less than three-times the upper limit of the physiological range. At the end of the study, four patients from the group receiving $5.5 \mu \mathrm{mol}$ and two patients from the group receiving $11 \mu \mathrm{mol}$ had a moderately increased ALT and AST (less than 100\% of the physiological upper limit). One patient from the group receiving $11 \mu \mathrm{mol}$ suffered from a mild normocytic anaemia at the end of the study $\left(3.6-3.9 \times 10^{12} 1^{-1}\right)$, but without any clinical symptoms or other changes in the blood count.

\section{Discussion}

The primary goal of this work was to investigate the relationship between MTX pharmacokinetics in plasma and PASI-score. In order to increase the range of values of 


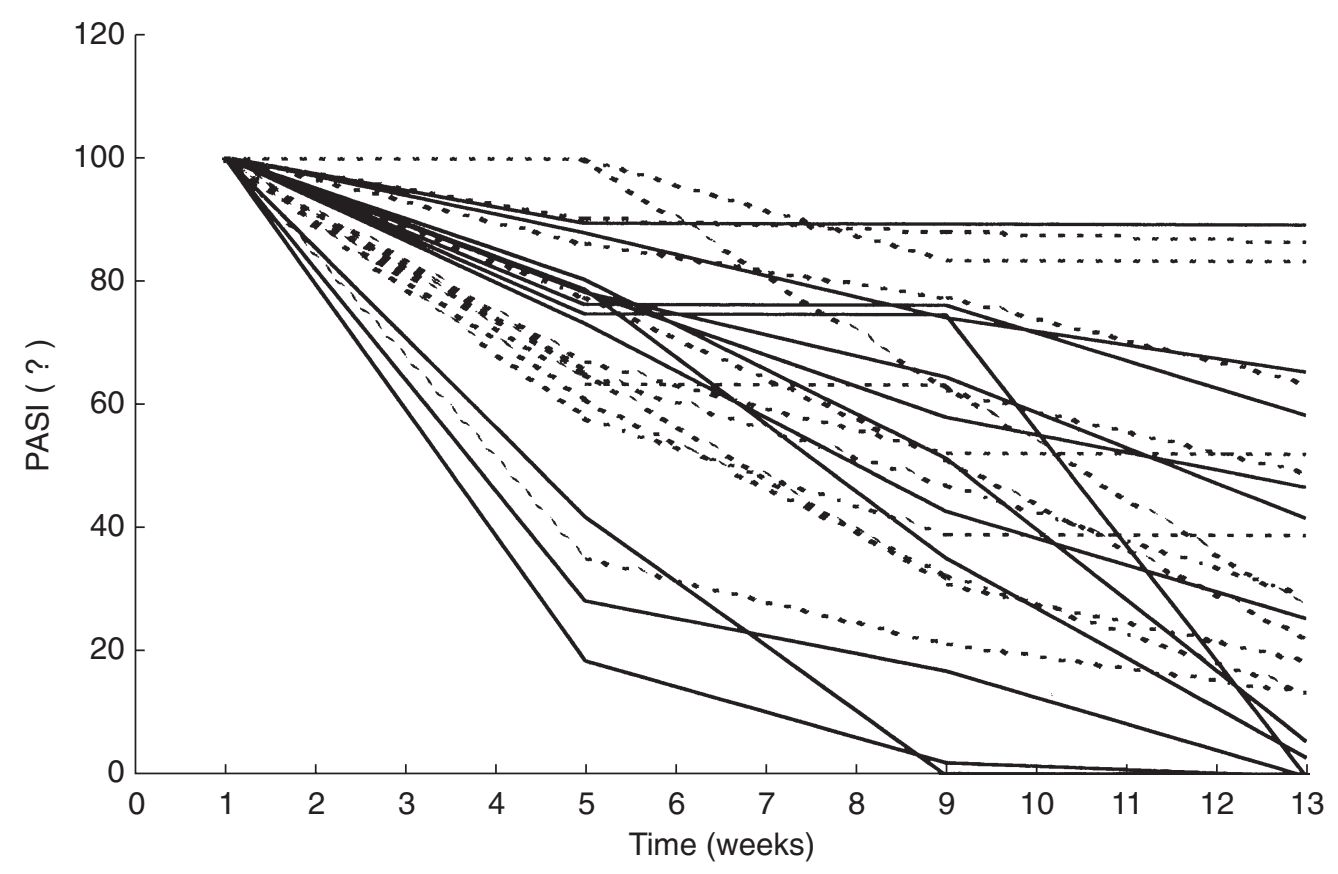

Figure 3 PASI-score during pharmacotherapy with low dose oral methotrexate given once a week with the weekly dose divided into three aliquots of either $2.5 \mathrm{mg}$ (broken lines, 12 patients) or $5 \mathrm{mg}$ (solid lines, 12 patients) given at $12 \mathrm{~h}$ intervals.

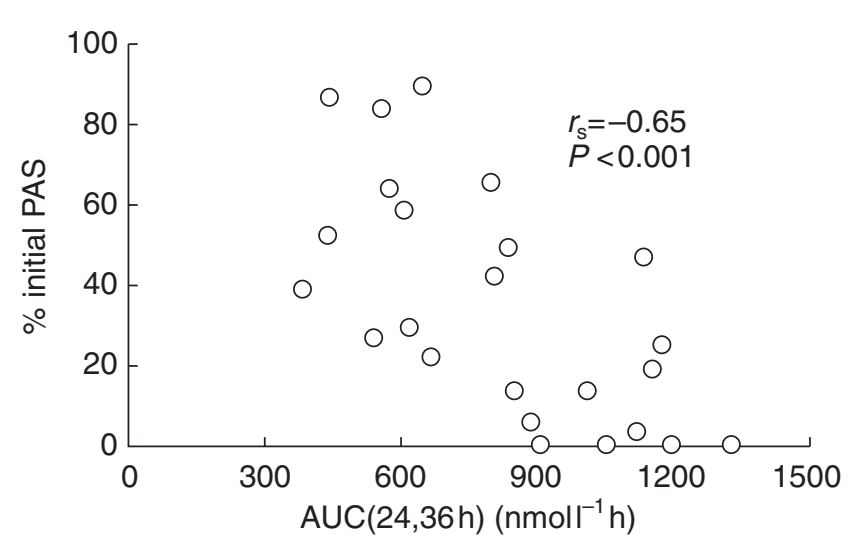

Figure 4 The relationship between $\mathrm{AUC}(24,36 \mathrm{~h})$ of methotrexate at week 1 of therapy and the final PASI score.

the target pharmacokinetic variable $\mathrm{AUC}_{\mathrm{MTX}}$, the patients were randomized to two parallel groups of $7.5 \mathrm{mg}$ and $15 \mathrm{mg}$ administered once a week with the weekly dose divided into three aliquots. According to the current guidelines, the two doses represent the upper limits of the starting range of doses for the triple-dose regimen [6]. This report is focused on an evaluation of the pharmacokinetics and pharmacodynamics of MTX in the first 3 months of therapy. Based on the published evidence and our own experience, this is a sufficient period of time both for the skin-clearing effect of the drug to develop and for the polyglutamate-form of MTX within cells to accumulate $[1,6]$. Our main finding was of a strong negative correlation between the final PASI score and the AUC $C_{\text {MTX }}$ in plasma, which confirms the result of our previous smaller study [8]. The fact that the study was open with regard to dosing probably did not introduce any bias, since both the final PASI-scores and percentages of responders to therapy were the same in the two groups (Table 1). Although randomized, the study groups were not balanced with the respect to gender and body size. This occurred by chance and would not affect the study conclusions.

Recently, a significant correlation was reported between the $A U C_{M T X}$ and both morning stiffness and the Ritchie articular index in patients with rheumatoid arthritis [13]. Except for our previous work, there are no other studies showing a relationship between concentration and effect for drugs used in systemic antipsoriatic therapy.

The pharmacokinetics of LDMTX administered as a single oral dose of 5-25 $\mathrm{mg}$ has been well characterized in adult patients with rheumatoid arthritis [3, 14-16] and psoriasis $[2,6]$. Considerable interindividual variability in its pharmacokinetics appears to be the most important feature complicating its clinical use and has forced doctors to switch from oral to intramuscular or subcutaneous administration in the therapy of rheumatoid arthritis [7]. There are two main sources of variability in the pharmacokinetics of MTX. These are (1) the rate and extent of absorption, and (2) renal clearance. The mean absolute bioavailability of oral MTX is $0.7-0.8$. However, several investigators have reported large variations 
ranging from 0.3 to 0.9 between patients $[1,8,15,17]$. The magnitude of this difference may be even greater in psoriatics who have an increased incidence of malabsorptive enteropathy [1]. It is unlikely that the absorbed fraction is dose-dependent over the range $7.5-25 \mathrm{mg}$. The mean oral clearance of MTX in 7 out of 9 published studies was within a narrow range of $8.7-11 \mathrm{l} \mathrm{h}^{-1}[8,15-19,21,22]$. Two studies provided somewhat lower values of $61 \mathrm{~h}^{-1}$ after doses of $7.5 \mathrm{mg}$ and $15 \mathrm{mg}$, respectively [16, 17]. However, there is evidence of a decreased rate of absorption with the increasing oral dose as well as after administration in the fed state. In a recent population study, the inclusion of dose as a covariant and the fed $v$ s fasted state as a categorical predictor in the model decreased interindividual variability in $k \mathrm{a}_{\mathrm{po}}$ from $134 \%$ to of $77 \%$ [23]. Unfortunately, the authors did not test for the possible effect of dose on bioavailability. Our present parallelgroup study was of insufficient power to test for the differences in MTX pharmacokinetics after the two doses. Such a study would require a more efficient crossover design. Moreover, although patients were randomized, there were differences between the two groups in demographic characteristics such as body-weight and gender. It can be concluded that increasing the dose up to $30 \mathrm{mg}$ will probably lead, in most patients, to a linear increase in $\mathrm{AUC}_{\mathrm{MTX}}$, but to a lower than proportional increase in $C_{\max }$, and to a somewhat increased $t_{\max }$ as a consequence of a decreased rate of absorption of the drug $[14,15,17,19]$.

Renal clearance of unchanged drug is the principal mechanism of MTX excretion. The drug is filtered in the renal glomeruli and, also, undergoes active secretion and reabsorption across the renal tubules, utilizing the multispecific transporters common for a wide variety of endogenous substances, xenobiotics, and their metabolites [24]. Several studies including the present on show that after LDMTX, renal clearance is $2-28 \%$ higher than $\mathrm{CL}_{\mathrm{CR}}$ $[1,16,22,24,25]$. The tubular secretion of MTX prevails over its reabsorption and net renal clearance is about 2.5-fold higher than its glomerular filtration rate (Tables 1 and 5). After LDMTX, the tubular MTX secretion is not saturated, whereas saturation of the tubular reabsorption may occur. Moreover, the renal clearance of MTX is strongly affected by urinary $\mathrm{pH}$ as shown after high-dose chemotherapy [26]. These factors may contribute to the 4- to 5-fold variability in MTX renal clearance between subjects observed in the present study as well as in other studies [1, 8, 15, 16]. Kremer et al. [16] reported a decrease in renal clearance of MTX after 6 months of LDMTX therapy. The present study did not reveal such changes over a period of 13 weeks. The present data on the renal excretion of MTX and 7-OHMTX agree well with our previous findings [8] and those of Seideman et al. [27], who described that within $24 \mathrm{~h}$ after administration, over $80 \%$ of a dose of methotrexate is eliminated unchanged in the urine and about 3\% is excreted as 7-OHMTX.

To the best of our knowledge, no detailed pharmacokinetic study has been published on oral LDMTX administered using a triple-dose regimen. In the present study, the total oral clearance was estimated assuming a steady-state in MTX concentrations after the third weekly dose. This is a valid assumption supported by the result of the repeated-measures ANOVA. Moreover, the third dose was administered at $24 \mathrm{~h}$ after the start of dosing, that is, after at least four elimination half-lives $(5-6 \mathrm{~h})$. The median total oral clearance of $10.61 \mathrm{~h}^{-1}$ and the 4-fold intersubject variability in MTX pharmacokinetics are in good agreement with the data from single-dose studies published by others as well as from our previous study $[8,15-19,21,22,28]$. The MTX accumulation ratio of about 1.1 confirms the idea that MTX does not accumulate in plasma. Contrary to the parent drug, 7-OHMTX accumulates in plasma 2.5-fold after the third weekly dose. The exposure of the body to the metabolite relative to the parent drug is thus higher than that after a single-dose. Both MTX and the metabolite undergo enterohepatic circulation and the lower renal clearance of 7-OHMTX may contribute to its accumulation.

The rationale for therapeutic drug monitoring is based on several prerequisites. LDMTX meets at least three of these, namely a large interindividual variability in pharmacokinetics, a relationship between plasma concentrations and effect, and a considerable time period between dosing and the development of a clinical effect. Our finding of a low intraindividual variability and a lack of effect of the duration of therapy on methotrexate pharmacokinetics agrees with previous reports covering intermediate (13 weeks [8]), and long-term periods of dosing (6 months to 2 years $[15,16])$. Therapeutic drug monitoring and dose individualization only at the start of therapy seems to be warranted with possible additional examination of MTX pharmacokinetics in patients showing an unsatisfactory response. As a logical extension of this study, we attempted to define a 'therapeutic range' for a target value for the plasma AUC. Our findings suggest that for a triple-dose regimen, a steady state $\mathrm{AUC}_{\mathrm{MTX}}$ of $700 \mathrm{nmol} \mathrm{1}^{-1} \mathrm{~h}$ and higher, is desirable for greater than $50 \%$ decrease in PASI which defines response to the therapy. To improve the practicability of this aproach, a limited sampling strategy can be used to estimate AUC. By our experience as well as of others [29] such a strategy works well with two or better still three concentrations. It can be recommended that the triple dose regimen should be started with the higher weekly dose of $15 \mathrm{mg}$, 
because only 4 of 12 patients receiving the lower dose had an AUC value higher than $700 \mathrm{nmol}^{-1} \mathrm{~h}$.

There were no significant alterations in haematological or biochemical profiles, reflecting the lack of systemic side-effects. However, after the response has been achieved, titration of the lowest effective dose for a particular patient, as well as careful monitoring of systemic toxicity during maintenance pharmacotherapy, are mandatory.

In conclusion, a strong correlation was observed between MTX pharmacokinetics in plasma and its antipsoriatic effect after oral intermittent LDMTX administered as a triple-dose regimen. This finding together with considerable interindividual variability and low intraindividual variability in MTX pharmacokinetics support the role for therapeutic monitoring and dose individualization at the start of pharmacotherapy. The results suggest that a steady state $\mathrm{AUC}_{\mathrm{MTX}}$ of $700 \mathrm{nmol} 1^{-1} \mathrm{~h}$ and higher is associated with a significantly better success rate with MTX than lower values.

This study was supported financially by COST B15 (European Cooperation in the Field of Scientific and Technical Research), the government of the Czech Republic, and by a grant from Charles University in Prague, no. 9/99. We wish to acknowledge the contribution to this study of the personnel in the Departments of Dermatology and Pharmacology, Charles University in Prague, Faculty of Medicine in Hradec Králové, the Czech Republic.

\section{References}

1 Hendel J, Nyfors A. Non-linear renal elimination kinetics of methotrexate due to saturation of renal tubular reabsorption. Eur J Clin Pharmacol 1984; 26: 121-124.

2 Van Dooren-Greebe JR, Kuipers ALA, Mulder JTh, De Boo Van de Kerkhof PCM. Methotrexate revisited. Effects of long-term treatment in psoriasis. Br J Dermatol 1994; 130: 204-210.

3 Bannwarth B, Pehourcq F, Schaeverbeke T, Dehais J. Clinical pharmacokinetics of low-dose methotrexate in rheumatoid arthritis. Clin Pharmacokinet 1996; 30: 194-210.

4 Songsiridej N, Furst DE. Methotrexate - the therapy rapidly acting drug. Baillieres Clin Rheumatol 1990; 4: 575-593.

5 Tishler M, Caspi D, Yaron M. Methotrexate treatment of rheumatoid arthritis: is a fortnightly maintenance schedule enough? Ann Rheum Dis 1992; 51: 1330-1331.

6 Roenigk HH, Mailbach HI. Psoriasis, eds Shalita AR, Norris DA. Marcel Dekker Inc, 3rd edn., 1992, pp. 609-629.

7 Bannwarth B, Labat L, Moride Y, Schaeverbeke T. Methotrexate in rheumatoid arthritis. An update. Drugs 1994; 47: 25-50.

8 Chládek J, Martínková J, Šimková M, Vanièková J, Koudelková V. No??ièková M. Pharmacokinetics of low doses of methotrexate in patients with psoriasis over the early period of disease. Eur J Clin Pharmacol 1998; 53: $437-444$.
9 Finlay AY, Khan GK, Luscombe DK, Salek MS. Validation of sickness impact profile and psoriasis disability index in psoriasis. Br J Dermatol 1990; 123: 751-756.

10 Šalamoun J, František J. Determination of methotrexate and its metabolites 7-hydroxymethotrexate and 2,4 diamino-N10methylpteroic acid in biological fluids by liquid chromatography with fluorimetric detection. J Chromatogr 1986; 378: 173-181.

11 Sasaki K, Hosoya R, Wang YM, Raulston GL. Formation and disposition of 7-hydroxymethotrexate in rabbits. Biochem Pharmacol 1983; 32: 503-507.

12 Beck O, Seideman P, Wennberg M, Peterson C. Trace analysis of methotrexate and 7-hydrozymethotrexate in human plasma and urine by a novel high-performance liquid chromatographic method. Ther Drug Monit 1991; 13: 528-532.

13 Bologna C, Anaya JM, Bressolle F, Jorgensen C, Laric R, Sany J. Correlation between methotrexate pharmacokinetic parameters, and clinical and biological status in rheumatoid arthritis patients. Clin Exp Rheumatol 1995; 13: 465-470.

14 Ahern M, Booth J, Loxton A, et al. Methotrexate kinetics in rheumatoid arthritis: is there an interaction with nonsteroidal anti-inflammatory drugs? J Rheumatol 1988; 15: $1356-1360$.

15 Lebbe C, Beyeler C, Gerber NJ, Reichen J. Intraindividual variability of the bioavailability of low dose methotrexate after oral administration in rheumatoid arthritis. Ann Rheum Dis 1994; 53: 475-477.

16 Kremer JM, Petrillo GF, Hamilton RA. Pharmacokinetics and renal function in patients with rheumatoid arthritis receiving a standard dose of oral weekly methotrexate: association with significant decreases in creatinine clearance and renal clearance of the drug after 6 months of therapy. J Rheumatol 1995; 22: 38-40.

17 Oguey D, Köllinker F, Gerber NJ, Reichen J. Effect of food on the bioavailability of low-dose methotrexate in patients with rheumatoid arthritis. Arthritis Rheum 1992; 35: 611-614.

18 Kamel RS, Al-Hakiem MH, Rademaker M, Thomas RHM, Munro DD. Pharmacokinetics of small doses of methotrexate in patients with psoriasis. Acta Derm Venerol (Stockh) 1987; 68: 267-270.

19 Herman RA, Veng-Pedersen P, Hoffman J, Koehnke R, Furst E. Pharmacokinetics of low-dose methotrexate in rheumatoid arthritis patients. J Pharm Sci 1989; 78: 165-171.

20 Sinnett MJ, Groff GD, Raddatz A, Franck WA, Bertino JS. Methotrexate pharmacokinetics in patients with rheumatoid arthritis. J Rheumatol 1989; 16: 745-748.

21 Stewart CF, Evans WE. Drug-drug interactions with antirheumatic agents. Review of selected clinically important interactions. J Rheumatol 1990; 17(Suppl 22): 16-23.

22 Tracy TS, Worster T, Bradley JD, Greene PK, Brater DC. Methotrexate disposition following concomitant administration of ketoprofen, piroxicam and flubiprofen in patients with rheumatoid arthritis. Br J Clin Pharmacol 1994; 37: 453-456.

23 Godfrey C, Sweeney K, Miller K, Hammliton R, Kremer J. The population pharmacokinetics of long-term methotrexate in rheumatoid arthritis. $\mathrm{Br} \mathrm{J}$ Clin Pharmacol 1998; 46: 369-376.

24 Shen DD, Azarnoff DL. Clinical pharmacokinetics of methotrexate. Clin Pharmacokinet 1978; 3: 1-13. 
25 Anaya JM, Fabre D, Bressolle F, et al. Effect of etodolac on methotrexate pharmacokinetics in patients with rheumatoid arthritis. J Rheumatol 1994; 21: 203-208.

26 Sand TE, Jacobsen S. Effect of urine $\mathrm{pH}$ and flow on renal clearance of methotrexate. Eur J Clin Pharmacol 1981; 19: 453-456.

27 Seideman P, Beck O, Eksborg S, Wennberg M. The pharmacokinetics of methotrexate and 7-hydroxy metabolite in patients with rheumatoid arthritis. BrJ Clin Pharmacol 1993; 35: 409-412.
28 Combe B, Edno L, Lafforgue P, et al. Total and free methotrexate pharmacokinetics, with and without piroxicam, in rheumatoid arthritis patients. Br J Rheumatol 1995; 34: 421-442.

29 Eksborg S, Albertioni F, Beck O, Peterson C, Seideman P. Methotrexate in rheumatoid arthritis - a limited sampling strategy for estimation of the area under the plasma concentration versus time curve. Ther Drug Monit 1994; 16: $560-563$. 